TẠP CHÍ KHOA HỌC ĐẠI HỌC TÂN TRÀO
ISSN: $2354-1431$

\title{
CÁC YẾU TỐ TÁC ĐộNG ĐẾN QUYẾT ĐỊNH THAM GIA DU LỊCH CộNG ĐỒNG CỦA NGƯờI DÂN ĐỊA PHƯƠNG HUYỆN LÂM BİNH, TİNH TUYÊN QUANG
}

\author{
Nguyễn Thị Quỳnh Huoong ${ }^{a,}{ }^{*}$, Đỗ Thị Trang ${ }^{a}$, Đỗ Thị Nguyệt Vang ${ }^{a}$, Nguyễn Hoàng Yến ${ }^{a}$ \\ ${ }^{a}$ Truờng Đại học Thuoong Mại \\ *Email:quynhhuong6166@gmail.com
}

\section{Thông tin bài viết}

Ngày nhận bài:

2/5/2020

Ngày duyệt đăng:

$10 / 6 / 2020$

Tù khóa:

Du lịch, Du lịch cộng đồng, người dân địa phuơng, huyện Lâm Bình, tỉnh Tuyên Quang

\begin{abstract}
Tóm tắt
Huyện Lâm Bình, tỉnh Tuyên Quang được đánh giá là điểm đến hội tụ đầy đủ những điều kiện cần và đủ để phát triển loại hình du lịch cộng đồng. Theo đó, việc xác định các yếu tố tác động tới quyết định tham gia du lịch cộng đồng của người dân địa phương tại Lâm Bình, Tuyên Quang đóng vai trò rất quan trọng. Trên cơ sở dữ liệu thứ cấp và dữ liệu sơ cấp thu thập được, bài nghiên cứu chỉ ra những yếu tố tác động đến quyết định tham gia du lịch cộng đồng của người dân địa phương: (1) Yếu tố cá nhân, (2) Tính hấp dẫn và hình ảnh điểm đến du lịch; (3) Sự hỗ trợ, đầu tư từ phía Nhà nước, chính quyền địa phương, các tổ chức, doanh nghiệp; (4) Ảnh hưởng của những người xung quanh; qua đó đề xuất các giải pháp nhằm thu hút người dân địa phương tham gia du lịch cộng đồng và phát triển mạnh mẽ du lịch cộng đồng tại huyện Lâm Bình, tỉnh Tuyên Quang trong thời gian tới.
\end{abstract}

\section{1. ĐẶT VẤN ĐỀ}

Với lợi thế tài nguyên du lịch đa dạng, phong phú, ngành du lịch ở Việt Nam đang đóng vai trò ngày càng quan trọng trong nền kinh tế Việt Nam. Việt Nam đã và đang trở thành một điểm đến du lịch hấp dẫn với nhiều loại hình du lịch hấp dẫn: du lịch tham quan; du lịch nghỉ dưỡng, du lịch trải nghiệm; du lịch kết hợp với các hội thảo, hội nghị, sự kiện;... Tuy nhiên, làm du lịch như thế nào cho phù hợp với xu thế chung của thời đại và để phát triển được bền vững, du lịch Việt Nam cần quan tâm, phát triển tới loại hình du lịch cộng đồng (DLCĐ). Trên thực tế, DLCĐ đã được nhiều địa phương như Sapa (Lào Cai), Mộc Châu (Sơn La), Trà Quế (Hội An),... nghiên cứu và phát triển, mang lại hiệu quả tích cực cho ngành du lịch nói chung và người dân địa phương (NDĐP) tham gia loại hình du lịch này nói riêng. Từ sự thành công của các địa phương trên, huyện Lâm Bình, tỉnh Tuyên Quang cũng đang dần nghiên cứu và đầu tư phát triển loại hình du lịch này. Tuy nhiên, quá trình đầu tư, phát triển của Lâm Bình vẫn còn nhiều khó khăn, vướng mắc dẫn đến khả năng tham gia của người dân địa phương vào $\mathrm{DLC} Đ$ còn gặp nhiều hạn chế; chưa phát huy được hết tiềm năng du lịch của Lâm Bình. Để có thể phát triển mạnh mẽ hơn loại hình DLCĐ tại Lâm Bình và khuyến khích người dân tích cực tham gia thì việc xác định các yếu tố tác động đến quyết định tham gia DLCĐ của người dân địa phương trở nên rất cần thiết; có ý nghĩa cả về lý luận và thực tiễn. 


\section{TỔNG QUAN VÀ PHƯƠNG PHÁP NGHIÊN Cú́U}

\subsection{Tổng quan nghiên cứu}

Trong những năm gần đây, chủ đề DLCĐ; sự tham gia của người dân địa phương vào $\mathrm{DLC} Đ$ đã và đang nhận được rất nhiều sự quan tâm từ các nhà nghiên cứu trong và ngoài nước.

Theo các nghiên cứu, sự tham gia của cộng đồng dân cư địa phương được xem là một công cụ hữu hiệu và luôn được mong đợi như là một thành tố quan trọng thúc đẩy phát triển du lịch (Tosun, 2000; Aref và Redzuan, 2008). Về mặt khái niệm, sự tham gia của cộng đồng trong phát triển kinh tế thường được luận giải theo hai hướng: (1) Là quá trình theo đó sự tham gia ảnh hưởng đến tiến trình hoạch định, thực hiện và kết quả phát triển;

(2) Là cơ chế mà theo đó năng lực của cộng đồng được củng cố để giải quyết các vấn đề của họ và thúc đẩy khả năng tự thích ứng (Simmons, 1994; Reed, 1997).

Đối với phát triển du lịch, sự tham gia của cộng đồng dân cư địa phương lại được tiếp cận theo hướng kết quả với sự kết hợp của cả hai quan điểm trên nhằm hướng tới sự phân phối công bằng hơn các lợi ích kinh tế cho cộng đồng địa phương (Brohman, 1996; Aref và Redzuan, 2008). Có thể đánh giá đây là cách tiếp cận hợp lý có thể giải thích sự hình thành của một cơ chế mà trong đó có sự tham gia thực sự của người dân trong phát triển du lịch theo hướng bền vững.

Khi nghiên cứu về thái độ của cộng đồng thì một số nhà nghiên cứu cho rằng ý kiến của người dân về việc phát triển du lịch trong một cộng đồng địa phương phụ thuộc vào nhiều yếu tố khác nhau như mức độ phát triển du lịch của địa phương đó, sự nhận thức của người dân về lợi ích cũng như tính bền vững của điểm đến nói chung (Jamal, T.B; Getz, D, 1995; Phạm Trung Lương, 2002; Phạm Hồng Long, 2012).

Đối với một số nghiên cứu cụ thể về DLCĐ, các quan điểm về các điều kiện phát triển DLCĐ được các nhà nghiên cứu chỉ ra: (1) Cần có nguồn tài nguyên tự nhiên và nhân văn hấp dẫn; (2) Cần có khả năng tiếp cận điểm đến DLCĐ; (3) Cần có sự hiện diện của cộng đồng; (4) Cần có sự tự nguyện của cộng đồng; (5) Cần có nhu cầu đối với sản phẩm DLCĐ; (6) Điểm đến DLCĐ cần được quy hoạch (Bùi Xuân Nhàn, Nguyễn Thị Quỳnh Hương, 2019; Lê Thị Hồng Gái, 2019).
Như vậy, thông qua tổng quan một số nghiên cứu điển hình về DLCĐ và sự tham gia của cộng đồng dân cư địa phương vào phát triển du lịch nói chung, có thể thấy:

Các nghiên cứu đã đưa ra các quan điểm về DLCĐ; đặc biệt thể hiện sự tranh luận về các khía cạnh khác nhau của sự tham gia của cộng đồng NDĐP vào phát triển du lịch. Có nhiều yếu tố khác nhau ảnh hưởng tác động đến quyết định tham gia của NDĐP vào phát triển du lịch nói chung và DLCĐ nói riêng. Sự đa dạng của các yếu tố này phụ thuộc vào các điều kiện phát triển cũng như bối cảnh của từng địa phương. Theo đó, để xác định được các yếu tố tác động đến quyết định tham gia DLCĐ của NDĐP huyện Lâm Bình, tỉnh Tuyên Quang cần thực hiện nghiên cứu khám phá các yếu tố ảnh hưởng với các giả thiết nghiên cứu; từ đó làm cơ sở đề xuất cho các giải pháp nhằm thu hút NDĐP quyết định tham gia DLCĐ và phát triển mạnh mẽ DLCĐ tại huyện Lâm Bình, tỉnh Tuyên Quang.

\subsection{Phương pháp nghiên cứu}

\section{Phương pháp thu thập dữ liệu}

Nguồn dũ liệu thư cấp: Dũ̃ liệu thứ cấp được sử dụng cho nghiên cứu bao gồm sách chuyên khảo, đề tài NCKH các cấp, các bài báo có liên quan tại Thư viện Quốc gia Việt Nam, Thư viện Đại học Thương mại, các số liệu thống kê của Tổng cục Du lịch Việt Nam, Tổ chức Du lịch thế giới (UNWTO) và một số trang điện tử trong nước. Dữ liệu thứ cấp thực tế về các nhân tố ảnh hưởng tới quyết định tham gia của NDĐP vào DLCĐ Lâm Bình, Tuyên Quang: các báo cáo và số liệu thống kê của UBND tỉnh Tuyên Quang.

Nguồn dũ liệu sơ cấp: Dũ liệu sơ cấp được thu thập thông qua phỏng vấn sâu 7 chuyên gia về du lịch; 3 nhà quản lý địa phương và điều tra bằng bảng hỏi cho NDĐP tại huyện Lâm Bình, tỉnh Tuyên Quang. Phỏng vấn, điều tra, khảo sát được tiến hành trong khoảng thời gian từ 10/2019 đến 12/2019.

Trong nghiên cứu này, để đảm bảo kích thước mẫu khảo sát, tác giả sử dụng cách tính của Bollen (1998). Cách tính sẽ là $\mathrm{n} * 5$ quan sát (trong đó $\mathrm{n}$ là tham số ước lượng hay chính là thang đo cho các yếu tố). Cụ thể, bài nghiên cứu có 4 yếu tố với 19 biến quan sát. Như vậy tổng các quan sát là $19 * 5=95$ quan sát. Tuy nhiên, để đảm bảo tính khách quan và chính xác hơn, nhóm nghiên cứu đã phát ra 120 phiếu cho NDĐP tại huyện Lâm Bình, tỉnh Tuyên Quang. Số phiếu hợp lệ thu về là 105 phiếu, đảm bảo yêu cầu về mẫu điều tra. 


\section{CƠ SỞ LÝ LUẬN VÀ KHUNG NGHIÊN CÚUU ĐỀ XUẤT}

\subsection{Du lịch cộng đồng}

Trên thực tế đã có khá nhiều các quan điểm và cách tiếp cận khác nhau về DLCĐ được đưa ra. Theo nhà nghiên cứu Nicole Hausle và Wollfgang Strasdas (2009): “Du lịch cộng đồng là một hình thái du lịch trong đó chủ yếu là người dân địa phương đứng ra phát triển và quản lý. Lợi ích kinh tế có được từ du lịch sẽ đóng góp vào nền kinh tế địa phương".

Theo quan niệm trong tiêu chuẩn của ASEAN thì "Du lịch cộng đồng là một loại hình du lịch tìm kiếm cơ hội trao quyền cho cộng đồng trong việc quản lý mức độ tăng trưởng của du lịch và đạt được những mục tiêu có liên quan tới phúc lợi và phát triển bền vững về kinh tế, xã hội và môi trường".

Như vậy, từ các niệm trên, DLCĐ được hiểu là "Hoạt động du lịch do cộng đồng làm chủ, thực hiện, quản lý hoặc điều hành tại địa phương. DLCĐ mang lại cho du khách những trải nghiệm về cuộc sống địa phương, trong đó các cộng đồng địa phương tham gia trực tiếp vào các hoạt động du lịch và thu được các lợi ích kinh tế - xã hội từ các hoạt động du lịch; chịu trách nhiệm bảo vệ tài nguyên thiên, môi trường và văn hoá địa phương".

\section{Các lọi ích tù̀ du lịch cộng đồng}

Du lịch cộng đồng đem lại nhiều tác động tích cực đến cộng đồng dân cư, cụ thể: Cung cấp cơ hội, tạo thêm việc làm cho cộng đồng địa phương; Tạo điều kiện để phát triển kinh tế địa phương thông qua việc bán các sản phẩm và dịch vụ du lịch; Góp phần bảo tồn và phát huy các giá trị văn hoá bản địa; Cung cấp thị trường cho hàng hoá và dịch vụ địa phương; Góp phần nâng cao hình ảnh của địa phương và của quốc gia.

\subsection{Vai trò của người dân địa phương trong phát triển du lịch cộng đồng}

Cộng đồng dân cư địa phương đóng vai trò quan trọng, có ý nghĩa lớn đối với sự phát triển DLCĐ của một điểm đến du lịch, cụ thể: Thú nhất, cộng đồng dân cư địa phương góp phần quan trọng trong việc lưu giữ tài nguyên du lịch cốt lõi đó là bản sắc văn hóa và các làng nghề truyền thống. Thú hai, trong việc tham gia phát triển các sản phẩm du lịch, cộng đồng dân cư địa phương cung cấp các dịch vụ cấu thành nên một sản phẩm du lịch. Thứ $b a$, cộng đồng dân cư địa phương chính là người trực tiếp tham gia hoạch định các chương trình, dự án du lịch. Các dự án du lịch phải thỏa mãn được bốn lợi ích: nhà đầu tư, Nhà nước, cộng đồng và môi trường. Thư tux, cộng đồng dân cư địa phương là người bảo vệ tài nguyên môi trường du lịch.

Như vậy, cộng đồng dân cư địa phương vừa là yếu tố tạo nên sức hấp dẫn du khách đồng thời là đối tượng đáp ứng những nhu cầu của khách du lịch. Do vậy, việc tham gia và ủng hộ của cộng đồng dân cư địa phương vào phát triển DLCĐ không chỉ mang lại lợi ích cho họ và môi trường mà còn thu hút khách; nâng cao chất lượng du lịch, vị thế của điểm đến trên thị trường du lịch.

3.3. Các yếu tố ảnh hưởng đến quyết định tham gia du lịch cộng đồng của người dân địa phương huyện Lâm Bình, tỉnh Tuyên Quang

Trên cơ sở nghiên cứu, tổng quan tài liệu trong nước, ngoài nước cùng với kết quả phỏng vấn chuyên gia, các yếu tố ảnh hưởng và các biến quan sát tác động đến quyết định tham gia DLCĐ của người dân địa phương huyện Lâm Bình, tỉnh Tuyên Quang được xác định như sau:

Bảng 1: Các yếu tố ảnh hưởng đến quyết định tham gia du lịch cộng đồng của người dân địa phương huyện Lâm Bình, tỉnh Tuyên Quang

\begin{tabular}{|c|c|c|}
\hline Thành phần & Biến quan sát & Nguồn tham khảo \\
\hline 1. Yếu tố cá nhân & $\begin{array}{l}\text { [CN1] Mức độ gắn bó với quê hương } \\
\text { [CN2] Thu nhập cá nhân } \\
\text { [CN3] Lợi ích nhận được khi tham gia } \\
\text { [CN4] Sở thích làm du lịch } \\
\text { [CN5] Trình độ văn hóa } \\
\text { [CN6] Sự am hiểu về giá trị tài nguyên du lịch địa } \\
\text { phương }\end{array}$ & $\begin{array}{l}\text { Michale (1985); Lise (2000); } \\
\text { Briedenhann và Wickens (2004); } \\
\text { Thakadu (2005); Liu (2006); } \\
\text { Kang (2008); Lee (2013); Dương } \\
\text { Thị Minh Phương (2015); } \\
\text { Nguyễn Thị Lê (2016); Nguyễn } \\
\text { Quốc Nghi, Nguyễn Thị Bảo } \\
\text { Châu và Trần Ngọc Lành (2012); } \\
\text { Ngô Thị Liên (2018); } \\
\text { chuyên gia bổ sung }\end{array}$ \\
\hline
\end{tabular}




\begin{tabular}{|c|c|c|}
\hline Thành phần & Biến quan sát & Nguồn tham khảo \\
\hline $\begin{array}{l}\text { 2. Tính hấp dẫn và hình } \\
\text { ảnh điểm đến du lịch } \\
\text { Lâm Bình, Tuyên } \\
\text { Quang }\end{array}$ & $\begin{array}{l}\text { [HA1 \} TNDL (tự nhiên, văn hóa) đặc sắc, phong phú } \\
\text { [HA2] Các SPDL đa dạng } \\
\text { [HA3] Giá cả tại điểm đến hợp lý } \\
\text { [HA4] An ninh, an toàn tại điểm đến tốt } \\
\text { [HA5] CSHT, VCKTDL đầy đủ, tiện nghi } \\
\text { [HA6] Khả năng tiếp cận điểm đến thuận lợi } \\
\text { [HA7] Các hoạt động xúc tiến quảng bá hình ảnh điểm } \\
\text { đến tốt }\end{array}$ & $\begin{array}{l}\text { Hoàng Thị Lan (2019); } \\
\text { chuyên gia bổ sung }\end{array}$ \\
\hline $\begin{array}{l}\text { 3. Sự hỗ trợ, đầu tư từ } \\
\text { phía Nhà nước, Chính } \\
\text { quyền địa phương, các } \\
\text { tồ chức, doanh nghiệp } \\
\text { tại Lâm Bình, Tuyên } \\
\text { Quang }\end{array}$ & $\begin{array}{l}\text { [HT1] Các chính sách phát triển du lịch tại địa phương } \\
\text { [HT2] Sự đầu tư vào phát triển DL địa phương } \\
\text { [HT3] Các chính sách khuyến khích NDĐP tham gia } \\
\text { DLCĐ tại địa phương }\end{array}$ & $\begin{array}{l}\text { Bramwell \& Sharman (2000); } \\
\text { Kan (2009); Bandit (2009); } \\
\text { Kalsom (2009); Nguyễn Thị } \\
\text { Quỳnh Hương (2018); } \\
\text { chuyên gia bổ sung }\end{array}$ \\
\hline $\begin{array}{l}\text { 4. Ảnh hưởng của } \\
\text { những người xung } \\
\text { quanh }\end{array}$ & $\begin{array}{l}\text { [NXQ1]Gia đình khuyến khích tham gia làm du lịch } \\
\text { [NXQ2] Bạn bè, hàng xóm tham gia làm du lịch } \\
\text { [NXQ3] Những thành công của những người dân ở địa } \\
\text { phương khác tham gia vào phát triển DLCĐ }\end{array}$ & Chuyên gia bổ sung \\
\hline
\end{tabular}

(Nguồn: Tổng hơp của nhóm nghiên cưu)

Từ việc xác định được 4 yếu tố thành phần và 19 biến quan sát; nhóm nghiên cứu đề xuất phương trình hồi quy đa biến để kiểm định các nhân tố ảnh hưởng đến quyết định tham gia DLCĐ của người dân địa phương ở Lâm Bình, Tuyên Quang như sau:

$Q \boxplus T G=\beta 0+\beta 1 * C N+\beta 2 * H A+\beta 3 * H T+\beta 4 * N X Q+e$

Trong đó: QĐTG là biến phụ thuộc và các biến $\mathrm{CN}, \mathrm{HA}, \mathrm{HT}, \mathrm{NXQ}$ là các biến độc lập (biến giải thích).

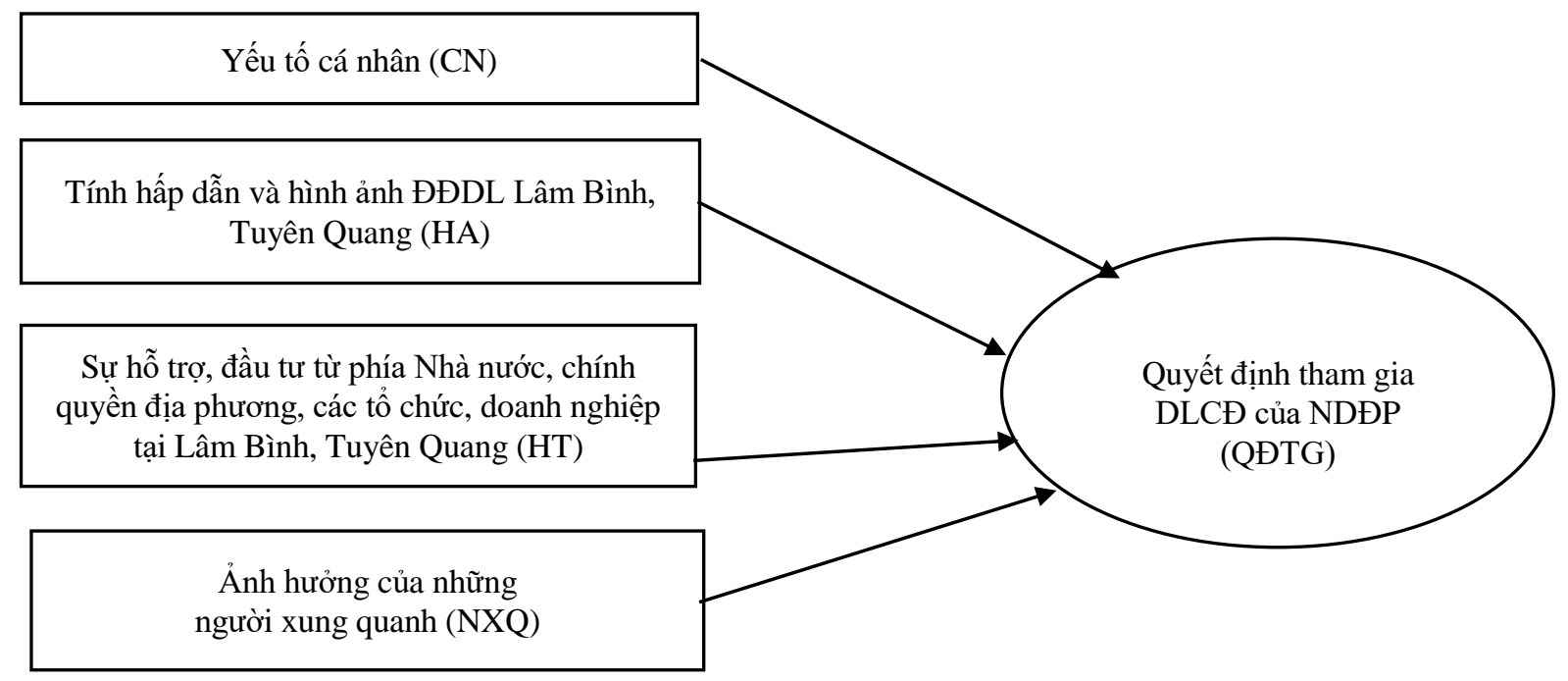

\section{Sơ đồ 1. Khung nghiên cứu các yếu tố ảnh hưởng đến quyết định tham gia DLCĐ của NDĐP tại huyện Lâm Bình, tỉnh Tuyên Quang}

Các giả thuyết nghiên cứu:

H1: Yếu tố cá nhân có mối quan hệ tương quan thuận với quyết định tham gia DLCĐ của NDĐP tại huyện Lâm Bình, tỉnh Tuyên Quang.

H2: Tính hấp dẫn và hình ảnh ĐĐDL Lâm Bình, Tuyên Quang có mối quan hệ tương quan thuận với quyết định tham gia DLCĐ của NDĐP tại huyện Lâm Bình, tỉnh Tuyên Quang.
(Nguồn: Đề xuất của nhóm nghiên cứu) H3: Sự hỗ trợ, đầu tư từ phía Nhà nước, chính quyền địa phương, các tổ chức, doanh nghiệp tại Lâm Bình, Tuyên Quang có mối quan hệ tương quan thuận với quyết định tham gia DLCĐ của NDĐP tại huyện Lâm Bình, tỉnh Tuyên Quang.

H4: Sự ảnh hưởng của những người xung quanh có mối quan hệ tương quan thuận với quyết định tham gia DLCĐ của NDĐP tại huyện Lâm Bình, tỉnh Tuyên Quang. 


\section{KÊTT QUẢ NGHIÊN CÚU VÀ THẢO LUẬN}

4.1. Thực trạng phát triển du lịch cộng đồng và sự tham gia của người dân địa phương tại huyện Lâm Bình, tỉnh Tuyên Quang

Thời gian trước đây, du lịch vẫn còn khá mới mẻ với người dân địa phương Lâm Bình thì đến năm 2019 đã có sự chuyển biến rõ rệt, thể hiện qua tổng lượt khách và doanh thu từ du lịch của huyện. Theo dữ liệu được cung cấp của huyện Lâm Bình, năm 2017, huyện Lâm Bình còn là một trong những huyện mới triển khai đầu tư vào lĩnh vực du lịch; đồng thời có những hoạt động tích cực hơn trong công tác quảng bá và xúc tiến hình ảnh du lịch địa phương như: đón các đoàn báo chí, truyền thông của tỉnh; thực hiện các chuyến công tác học tập kinh nghiệm từ tỉnh bạn,... Những nỗ lực trong năm 2017 đã gây được sự quan tâm chú ý từ phía chính quyền và các doanh nghiệp đầu tư. Nhận thấy tiềm năng phát triển du lịch của địa phương rất phong phú, bắt đầu từ cuối năm 2018 Hợp tác xã thanh niên Thượng Lâm đã quyết định đầu tư vào làm du lịch. HTX đầu tư phát triển du lịch, xây dựng cơ sở homestay gắn với không gian văn hoá dân tộc Tày. Đến năm 2019, du lịch tại Lâm Bình có sự phát triển đáng kể, chủ yếu tập trung nhân rộng mô hình DLCĐ homestay, phát triển thêm các sản phẩm, dịch vụ du lịch đa dạng. Kết quả là tổng lượng khách đến trong năm 2019 đạt 120.000 lượt, tăng 300\% so với năm 2018 và doanh thu từ du lịch đạt 72 tỷ đồng. Qua đó, có thể thấy ngành du lịch đặc biệt là DLCĐ tại Lâm Bình, Tuyên Quang đang có nhiều dấu hiệu khởi sắc và vẫn còn nhiều tiềm năng để phát triển trong thời gian tới.

Thêm vào đó, được sự vận động, hỗ trợ của chính quyền địa phương, nhiều hộ gia đình đã sửa lại ngôi nhà sàn hoặc đầu tư xây mới để làm du lịch. Ngoài ra, các hộ gia đình còn nấu các món ăn truyền thống của dân tộc để phục vụ du khách có nhu cầu.

Bảng 2. Số lượng homestay tại huyện Lâm Bình năm 2017 - 2019

\begin{tabular}{|c|c|c|c|}
\hline Các xã & $\mathbf{2 0 1 7}$ & $\mathbf{2 0 1 8}$ & $\mathbf{2 0 1 9}$ \\
\hline Thượng Lâm & 6 & 6 & 6 \\
\hline Lăng Can & 5 & 5 & 4 \\
\hline Khuôn Hà & 4 & 4 & 4 \\
\hline Phúc Yên & 0 & 0 & 24 \\
\hline Tổng & 15 & 15 & \\
\hline
\end{tabular}

Bên cạnh các dịch vụ homestay, còn có các dịch vụ cho thuê thuyền và kayak khám phá lòng hồ sinh thái $\mathrm{Na}$ Hang - Lâm Bình. Song song với du lịch sinh thái việc giữ gìn và phát huy bản sắc văn hóa các dân tộc trên địa bàn cũng được người dân quan tâm. Các làn điệu dân ca, dân vũ được gìn giữ và khôi phục thông qua việc thành lập các đội văn nghệ, các câu lạc bộ hát then, hát cọi, hát Páo dung, múa khèn... Các sản phẩm du lịch từng bước được đầu tư đa dạng, phong phú, các dịch vụ phục vụ cũng được chuyên nghiệp hóa, tạo được ấn tượng tốt trong lòng du khách. Mặc dù người dân địa phương Lâm Bình đã dần ý thức được những lợi ích mà DLCĐ mang lại tuy nhiên, số hộ tham gia làm du lịch vẫn còn rất ít, phạm vi còn nhỏ lẻ, chính vì vậy thiếu đi sự liên kết cộng đồng để đáp ứng nhu cầu ngày càng cao của du khách. Câu hỏi đặt ra là những yếu tố nào đã ảnh hưởng đến quyết định tham gia DLCĐ của người dân và làm cách nào để thu hút họ tham gia phát triển $\mathrm{DLCĐ} \mathrm{tại} \mathrm{địa}$ phương.

4.2. Các yếu tố ảnh hưởng đến quyết định tham gia du lịch cộng đồng của người dân địa phương Lâm Bình, Tuyên Quang
Nghiên cứu sử dụng phần mềm SPSS 20.0 để hỗ trợ phân tích hồi quy đa biến với khung nghiên cứu và các dữ liệu thu thập được, nhóm nghiên cứu tiến hành đánh giá độ tin cậy của các thang đo bằng hệ số tin cậy Cronbach's Alpha.

Các thang đo sẽ được tiến hành kiểm định bằng công cụ Cronbach’s Alpha. Với Cronbach's Alpha sẽ giúp loại đi các biến quan sát không đạt yêu cầu hay các thang đo chưa đạt yêu cầu trong quá trình nghiên cứu.

Kết quả đánh giá hệ số tin cậy Cronbach's Alpha với các biến quan quan sát trong các thang đo đều lớn hơn 0.6 , các hệ số tương quan tổng biến quan sát phù hợp lớn hơn 0.3 . Như vậy, tất cả các thang đo đều đạt độ tin cậy, phù hợp để đưa vào phân tích nhân tố khám phá EFA.

\section{Phân tích nhân tố EFA}

Kết quả phân tích nhân tố EFA (sử dụng phép quay varimax) cho thấy hệ số $\mathrm{KMO}=0.903>0.5$ đạt yêu cầu, có ba yếu tố được trích ra tại Eigenvalue là $1.066>1$ và tổng phương sai trích là $87.533 \%>50 \%$. Đối với bảng ma trận xoay nhân tố, các biến đều có hệ số tải nhân tố 
(Factor loading) từ 0.5 trở lên. Kết luận thang đo các biến quan sát đưa vào phân tích đạt yêu cầu và có ý nghĩa.

Kiểm định tương quan

Phân tích tương quan Pearson được sử dụng trong phần này để xem xét sự phù hợp khi đưa các thành phần vào mô hình hồi qui. Hệ số tương quan Pearson (r) dùng để lượng hóa mức độ chặt chẽ của mối liên hệ tuyến tính giữa hai biến định lượng. Trị tuyệt đối của $r$ cho biết mức độ chặt chẽ của mối liên hệ tuyến tính.

$\mathrm{r}<=0.3$ : mối tương quan không chặt; $0.3<\mathrm{r}<0.5$ : mối tương quan tương đối chặt; $r>=0.5$ : mối tương quan chặt chẽ.

Giá trị sig cho biết mối quan hệ giữa các biến quan sát có ý nghĩa thông kê hay không. Ở đây, hệ số tương quan $\mathrm{r}$ đều lớn hơn 0.3 và giá trị sig đều $<0.01$ cho thấy các biến độc lập đều có mối quan hệ với biến phụ thuộc ở mức ý nghĩa 99\% và đều là các mối quan hệ thuận chiều.

\section{Mô hình hồi qui}

Khi kiểm định độ phù hợp của mô hình cho thấy ý nghĩa $<0.01$ (giá trị Sig. $=0.000<0.01$ ) chứng tỏ rằng với mức ý nghĩa $99 \%$ có thể bác bỏ giả thuyết cho rằng tất cả các hệ số hồi qui bằng 0 nghĩa là có mối quan hệ giữa biến độc lập và biến phụ thuộc. Giá trị $\mathrm{R}^{\wedge} 2=$ 0.948 và $R^{\wedge} 2$ hiệu chỉnh $=0.947$ có ý nghĩa là $94.7 \%$ sự biến thiên về quyết định tham gia DLCĐ được giải thích bởi các biến độc lập trong khung nghiên cứu.Vậy mô hình hồi qui được xây dựng là phù hợp với bộ dữ liệu thu thập được. Kết quả phân tích hồi qui đa biến như sau:

Bảng 4. Kết quả phân tích hồi quy đa biến

\begin{tabular}{|c|c|c|c|c|c|c|c|}
\hline \multirow{2}{*}{ Thang do } & \multicolumn{2}{|c|}{ Hệ số chưa chuẩn hoá } & \multirow{2}{*}{$\begin{array}{c}\begin{array}{c}\text { Hệ số } \\
\text { chuân hoá }\end{array} \\
\text { Beta }\end{array}$} & \multirow{2}{*}{ Giá trị t } & \multirow{2}{*}{$\begin{array}{c}\text { Mức ý } \\
\text { nghĩa Sig. }\end{array}$} & \multicolumn{2}{|c|}{$\begin{array}{c}\text { Thống kê } \\
\text { đa cộng tuyến }\end{array}$} \\
\hline & $\begin{array}{l}\text { Trọng số } \\
\text { hồi quy }\end{array}$ & Độ lệch chuẩn & & & & $\begin{array}{c}\text { Hệ số } \\
\text { chấp nhận }\end{array}$ & VIF \\
\hline Hằng số & .285 & .088 & & 3.254 & .001 & & \\
\hline $1 . \mathrm{CN}$ & .335 & .018 & .391 & 19.009 & .000 & .567 & 1.764 \\
\hline 2. HA & .159 & .023 & .116 & 6.764 & .000 & .816 & 1.225 \\
\hline 3. HT & .130 & .017 & .157 & 7.440 & .000 & .543 & 1.843 \\
\hline 4. NXQ & .388 & .013 & .550 & 29.184 & .000 & 677 & 1.477 \\
\hline
\end{tabular}

(Nguồn: Kết quả xủ lý dũ liệu tù SPSS 20.0 của nhóm nghiên cưu)

Như vậy, mô hình hồi quy đánh giá mức độ ảnh hưởng của các yếu tố tới Quyết định tham gia DLCĐ của NDĐP Lâm Bình, Tuyên Quang được viết lại như sau:

\section{$Q Ð T G=0,391 * C N+0,116 * H A+0,157 * H T+$ $0,550 * N X Q$ \\ 5. ĐỀ XUẤT GIẢI PHÁP PHÁT TRIỂN DU LICCH CộNG ĐỒNG TẠI LÂM BİNH, TUYÊN QUANG}

Xuất phát từ kết quả phân tích thực trạng và kết quả kiểm định các yếu tố ảnh hưởng đến quyết định tham gia DLCĐ của NDĐP tại huyện Lâm Bình, tỉnh Tuyên Quang, nhóm tác giả đề xuất một số các giải pháp nhằm phát triển DLCĐ tại Lâm Bình, Tuyên Quang trong thời gian tới, cụ thể:

Thú $n h a ̂ ́ t$, cần đầu tư vào cơ sở hạ tầng và cơ sở vật chất kĩ thuật du lịch tại huyện Lâm Bình. Uuu tiên vào sửa chữa, cứng hóa đường đất, xây dựng những tuyến đường chính dẫn đến các điểm đến du lịch, các tuyến đường liên kết giữa các vùng (giữa Lâm Bình với $\mathrm{Na}$ Hang, giữa tỉnh Tuyên Quang và Hà Giang) tạo thuận lợi cho du khách tiếp cận điểm đến huyện Lâm Bình, đồng thời thuận lợi để liên kết các tour du lịch xuyên suốt, đa dạng hóa sản phẩm du lịch.

Thư hai, cần phải đầu tư tu bổ, tôn tạo và nâng cấp một cách tổng thể các tài nguyên du lịch tại huyện Lâm
Bình, để tạo được ấn tượng về hình ảnh và thương hiệu điểm đến với khách du lịch. Việc quản lý, bảo vệ, tôn tạo các di sản văn hóa và thiên nhiên phải phù hợp cho việc phát triển du lịch, tạo tiền đề cho người dân tham gia vào công cuộc phát triển DLCĐ thu hút khách du lịch tới tham quan từ đó DLCĐ tại huyện Lâm Bình sẽ được chú ý hơn, phát triển hơn.

Thú $b a$, cần địa phương hóa các sản phẩm du lịch, phát triển các sản phẩm, dịch vụ du lịch trở nên đa dạng, độc đáo và nâng cao chất lượng hơn nữa để NDĐP thấy được sức cạnh tranh và khả năng thu hút khách du lịch của Lâm Bình. Trong đó, việc đầu tư nghiên cứu, phát triển vật phẩm, quà lưu niệm mang bản sắc văn hóa các dân tộc tại huyện Lâm Bình hay xây dựng tour tham quan ngắm cảnh bằng xe đạp là những biện pháp cần làm hiện tại để không những thu hút du khách mà còn để lại dấu ấn và giữ chân du khách. Đặc biệt, cần đề xuất công nhận tộc người Thuỷ - tộc người chỉ có duy nhất ở Tuyên Quang là một dân tộc anh em sẽ bảo tồn và phát triển được văn hoá của họ, theo đó có thể thúc đẩy người dân tộc Thuỷ tham gia vào DLCĐ tại địa phương cũng như giúp cho hình ảnh du lịch Lâm Bình được hấp dẫn và đa dạng màu sắc hơn nữa trong mắt du khách. 
$T h u ̛$ tu, cần nâng cao nhận thức về DLCĐ cho NDĐP. Để làm được điều này cần có sự nỗ lực hết mình của chính quyền xã, huyện trong các công tác tuyên truyền vận động đến NDĐP; tập huấn, đào tạo mô hình, kỹ năng làm DLCĐ; khắc phục khó khăn trong giao tiếp, đặc biệt là giao tiếp với người nước ngoài. Cần phải phổ biến cho người dân những dự án, những chương trình được đầu tư xây dựng tại Lâm Bình, và những thuận lợi để phát triển du lịch và lợi ích nhận được của NDĐP để họ nhận biết được tiềm năng du lịch tại địa phương và tích cực tham gia vào việc phát triển DLCĐ.

Thư năm, chính quyền địa phương cần thiết kế chương trình và tiến hành đào tạo bồi dưỡng về quản lý du lịch và DLCĐ cho cán bộ của địa phương, để từ đó triển khai xuống các hộ dân. Điều mà các hộ dân đang mong muốn là đường lối, định hướng đúng đắn cho DLCĐ của địa phương, nếu đáp ứng được mong muốn này có khả năng thúc đẩy người dân tự nguyện tham gia DLCĐ nhiều hơn, góp phần phát triển DLCĐ tại Lâm Bình.

Thư sáu, cần phân chia rõ ràng lợi ích nhận được của mỗi bên (những chủ thể tham gia vào phát triển các dự án DLCĐ: chính quyền địa phương, doanh nghiệp và $\mathrm{NDĐP)} \mathrm{để} \mathrm{đảm} \mathrm{bảo} \mathrm{không} \mathrm{có} \mathrm{sự} \mathrm{nghi} \mathrm{ngờ,} \mathrm{tranh} \mathrm{cãi,}$ xung đột khi cùng nhau tham gia phát triển DLCĐ. NDĐP tại Lâm Bình trình độ văn hóa chưa cao, họ không am hiểu về luật pháp cũng như các vấn đề kinh tế, bởi vậy cần tạo sự tin tưởng để họ sẵn sàng tham gia vào phát triển DLCĐ.

Thư bảy, khuyến khích NDĐP giúp đỡ và hỗ trợ nhau trong quá trình làm du lịch. Bản thân mỗi hộ gia đình, mỗi cá nhân NDĐP cần hướng đến lợi ích chung của cộng đồng mà sẵn sàng hỗ trợ, giúp đỡ những người xung quanh mình, những người chưa có kinh nghiệm làm DLCĐ để họ có bước khởi đầu tốt hơn từ đó củng cố niềm tin và động lực tiếp tục phát triển DLCĐ tại địa phương.

\section{KẾT LUẬN}

Trên cơ sở sử dụng các dữ liệu thứ cấp và sơ cấp thu thập được, nghiên cứu đã đề xuất được khung nghiên cứu và thông qua ứng dụng mô hình hồi quy đa biến, kết quả nghiên cứu đã chỉ ra 4 yếu tố ảnh hưởng tới quyết định tham gia DLCĐ của NDĐP tại Lâm Bình, Tuyên Quang bao gồm: Yếu tố cá nhân; Tính hấp dẫn và hình ảnh điểm đến du lịch; Sự hỗ trợ, đầu tư từ phía Nhà nước, chính quyền địa phương, các tổ chức, doanh nghiệp; Ảnh hưởng của những người xung quanh. Qua đó, bài viết đề xuất bảy giải pháp nhằm khuyến khích người dân địa phương Lâm Bình, Tuyên Quang tham gia tích cực vào $D L C Đ$ và phát triển bền vững $d u$ lịch Lâm Bình nói riêng và du lịch Tuyên Quang nói chung trong thời gian tới.

\section{TÀI LIỆU THAM KHẢO}

1. Bộ VHTTDL Việt Nam, Tổng Cục Du lịch, "Số liệu thống kê" các năm 2017, 2018, 2019

2. Nguyễn Đức Khoa (2010), "Nghiên cứu điều kiện phát triển du lịch cộng đồng ở huyện Na Hang, Tuyên Quang", Tạp chí Văn hóa Nghệ thuật, số 372

3. Nguyễn Anh Lợi (2020), "Giải pháp phát triển du lịch cộng đồng tại huyện Lâm Bình, tỉnh Tuyên Quang", Tạp chí Công Thương

4. Hoàng Thị Lan (2019), "Du lịch cộng đồng tại Lâm Bình, Tuyên Quang - Thực trạng và giải pháp phát triển”, Kỷ yếu Hội thảo quốc tế: Du lịch Lâm Bình - Tuyên Quang: Tiềm năng, thực trạng và giải pháp

5. Phạm Hồng Long (2012), "Local Residents' Perceptions of Tourism Impacts and Their Support for Tourim Development: the Case of Ha Long Bay, Quang Ninh, Viet Nam" (Luận án tiến sỹ, Trường Đại học Rikkyo, Nhật Bản).

6. Phạm Trung Lương (2010), "Tài liệu giảng dạy về du lịch cộng đồng”, Viện Nghiên cứu phát triển du lịch, Tổng cục Du lịch.

7. Hoàng Trọng và Chu Mộng Ngọc (2008), "Phân tích dữ liệu nghiên cứu với SPSS”, NXB Thống kê.

8. Ủy ban Nhân dân tỉnh Tuyên Quang (2016), "Kế hoạch phát triển du lịch tỉnh Tuyên Quang giai đoạn 2016 - 2020".

9. Aref, F. and Redzuan, M. B. (2008), "Barriers to community participation toward tourism development in Shiraz, Iran, Pakistan", Journal of Social Sciences, $5(9)$.

10. Brodman, J. (1996), "New direction in tourism for third world development", Annal of Tourism Research, 23 (1).

11. Jamal, T.B \& Getz, D. (1995), "Collaboration Theory and Community Tourism Planning", Annals of Tourism Research.

12. Reed, M. (1997), "Power relations and community-based tourism planning", Annals of Tourism Research. 24(3).

13. Sue Beeton (2006), "Community Development through Tourism", Landlinks.

14. Simmons, D. G. (1994), "Community participation in tourism planning", Tourism Management, 15(2). 


\section{Factors affects decisions to participate in community tourism of the local people in Lam Binh, Tuyen Quang}

Nguyen Thi Quynh Hurong, Do Thi Trang, Do Thi Nguyet Vang, Nguyen Hoang Yen

\begin{tabular}{l}
\hline Article info \\
\hline Recieved: \\
$2 / 5 / 2020$ \\
Accepted: \\
10/6/2020
\end{tabular}

Keywords:

Tourism, Community tourism, the local people, Lam Binh district, Tuyen Quang province

\begin{abstract}
Lam Binh, Tuyen Quang is considered as a destination that has full conditions to develop community tourism.. Then, determining the factors affecting decisions to join in community tourism of local people in Lam Binh, Tuyen Quang plays an extremely important role. By using secondary data and collected primary data, the research points out the factors affecting decisions to take part in community tourism of the local people: (1) Personal factors, (2) Attractiveness and image of destinations, (3) Support and investment of the State, local authorities, organizations, and businesses, (4) Influence of peole around them. Thereby, a number of implications are proposed to attract the local people to participate in community tourism and develop community tourism in Lam Binh, Tuyen Quang in the future.
\end{abstract}

